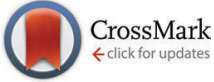

Cite this: Phys. Chem. Chem. Phys., $2016,18,27148$

Received 3rd June 2016 Accepted 26th August 2016

DOI: $10.1039 / c 6 c p 03851 d$

www.rsc.org/pccp

\section{Influence of the mixed organic cation ratio in lead iodide based perovskite on the performance of solar cells $\dagger$}

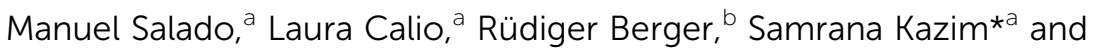 \\ Shahzada Ahmad*a
}

\begin{abstract}
Lead halide based perovskite solar cells are presently the flagship among the third generation solutionprocessed photovoltaic technologies. The organic cation part in the perovskite plays an important role in terms of crystal structure tuning from tetragonal to trigonal or pseudocubic or vice versa depending on the organic cations used, while it also displays different microstructure. In this paper, we demonstrate the influence of the organic cation part with respect to optical properties, hysteresis behavior, and stability. This study offers a clear understanding of the perovskite properties and how they can be modulated by compositional engineering. With a rational choice, light harvesting abilities and hysteresis behavior can be controlled in these systems. The substitution of formamidinium cation by methylammonium cation allows achieving low temperature annealing and inducing stability in perovskites together with enhanced photovoltaic properties. By the use of in-situ scanning force microscopy experiments the conversion of precursors to perovskite at a particular temperature can be visualized.
\end{abstract}

\section{Introduction}

Since the discovery of the photovoltaic (PV) effect in the nineteenth century, researchers have shown keen interest in the development of cost effective and efficient materials to convert solar energy into electricity. Currently, the major market share ( $c$. 91\%) is being controlled by silicon solar cells, among which monocrystalline silicon solar cells offer power conversion efficiencies (PCE) of $>25 \%$. Their high production cost and excessive usage of raw materials escalate their energy payback time and limit their wide application for grid parity. Over the last few decades, different technologies such as dye-sensitized solar cells (DSSCs), organic solar cells and inorganic thin film based solar cells have been extensively studied mainly due to their low amount of material needs, solution processable nature and cost competitiveness. ${ }^{1}$

In recent years, perovskite solar cells (PSCs) have stunned the PV field, given the tremendous research interest in them, owing to the unique combination of their high performance and the low-cost fabrication process. Compared with the existing technology, PSCs have demonstrated their potential by establishing

\footnotetext{
${ }^{a}$ Abengoa Research, C/Energía Solar $n^{o}$ 1, Campus Palmas Altas-41014, Sevilla, Spain.E-mail:shahzada.ahmad@abengoa.com, samrana.kazim@abengoa.com

${ }^{b}$ Max Planck Institute for Polymer Research, Ackermannweg 10, Mainz 55128, Germany

† Electronic supplementary information (ESI) available. See DOI: 10.1039/c6cp03851d
}

an unprecedented increment in the PCE from $3.8 \%{ }^{2}$ to $>22 \%$ (http://www.nrel.gov/ncpv/) in a short time frame. The panchromatic light-absorption ability along with high absorption coefficient, tuneable direct band gap and charge separation and transport capability of the organohalide perovskite materials makes them suitable as light absorber materials for PV applications., ${ }^{3,4}$ However, one of the concerns that need to be addressed is the stability and hysteresis behaviour in the devices. ${ }^{5}$ In a broader context the term perovskite refers to any material which follows the crystal structure of $\mathrm{ABX}_{3}$. In the case of hybrid organic-inorganic perovskite, A and B corresponds to organic and inorganic cations respectively, while $\mathrm{X}$ represents the halide anion. In order to balance the charge in the structure, the organic cation (A) occupies the cuboctahedral cavity formed by eight $\mathrm{PbI}_{6}$ octahedra. The size of the cation "A" can notably affect the symmetry of the octahedral network and alter the band gap. ${ }^{6}$ Theoretically, it is known that the three-dimensional (3D) perovskite is formed when its tolerance factor $(t)$ falls in the range of 0.7 to 1 as described by Goldschmidt. $^{7}$

Methylammonium $\left(\mathrm{CH}_{3} \mathrm{NH}_{3}{ }^{+}, \mathrm{MA}\right.$, ionic radius $\left.2.70 \AA\right)$ and formamidinium $\left(\mathrm{HC}\left(\mathrm{NH}_{2}\right)^{+}, \mathrm{FA}\right.$, ionic radius $\left.2.79 \AA\right)$ both satisfy the tolerance factor $(t)$ to form a 3D network. However, due to the slightly larger cation size of FA than MA, FA provides red shift of the absorption onset due to the change in the metal-halide-metal bond angle and leads to a narrower band gap $(1.48 \mathrm{eV})^{8,9}$ compared to $\mathrm{MAPbI}_{3}(1.57 \mathrm{eV}) .{ }^{10}$ Additionally, formamidinium lead iodide $\left(\mathrm{FAPbI}_{3}\right)$ shows almost equal or higher charge carrier 
mobility $\left(\sim 75 \mathrm{~cm}^{2} \mathrm{~V}^{-1} \mathrm{~s}^{-1}\right)$ depending on the processing method, ${ }^{11-13}$ better thermal stability at high temperature and negligible hysteresis during $J-V$ measurements as compared to $\operatorname{MAPbI}_{3} \cdot{ }^{9,14,15}$ However, it is difficult to prepare a uniform, fully covered surface of stable photoactive black polymorph ( $\alpha$-phase) of $\mathrm{FAPbI}_{3}$ perovskite due to its phase transition into yellow nonperovskite ( $\delta$-phase) at room temperature. The conversion to $\alpha$-phase of $\mathrm{FAPbI}_{3}$ is achieved at high temperature $\left(>140{ }^{\circ} \mathrm{C}\right)$.

The microstructure and phase purity of the thin film rely on the perovskite crystal formation processes. A variety of different deposition techniques have been used with the aim to achieve a high quality perovskite layer, such as a two step (sequential deposition) method, ${ }^{16}$ vacuum evaporation, ${ }^{17}$ vapour-assisted deposition ${ }^{18}$ or the recently developed solvent engineering approach. ${ }^{19}$ To establish a synergistic effect of both FA and MA organic cations opto-electrical properties, one of the suggested alternative was partial replacement of the MA cation by FA. So far, only a few studies have reported on the mixed organic cation of $\mathrm{MAPbI}_{3}$ and $\mathrm{FAPbI}_{3}$ using a two-step sequential method. ${ }^{14,20,21}$

These mixed organic cations exhibited PV performance superior to that of pure $\mathrm{MAPbI}_{3}$, due to their extended absorption in the red part of the spectrum, better semiconducting properties and high structural and thermal stability provided by the incorporation of the FA cation in the MAI lattice matrix. ${ }^{14,20}$ The band gap can be tuned by changing the mixed cation ratio and it has been found that it varies depending on the perovskite processing method. ${ }^{22}$ However, none of these studies addressed the hysteresis behaviour in the solar cells, which is crucial to understand the real figure of merit for PV devices.

In this paper, we have studied the structural, surface, optical, and photovoltaic properties of 3-dimensional mixed cation perovskites having a range of composition $\mathrm{MA}_{x} \mathrm{FA}_{(1-x)} \mathrm{PbI}_{3}(x=0-1)$ as light-harvesting materials in a mesoscopic solar cell configuration. The mesoscopic configuration was found to be ideal for the formation of $\alpha$-phase of $\mathrm{FAPbI}_{3}$. By utilizing the anti-solvent approach, during the one step deposition process of perovskites, it is possible to obtain dense morphology with high crystallinity and large crystals in a mixed cation environment. This deposition method also allows us to transform the rough perovskite film into a smooth and glossy perovskite, with the aim to obtain homogeneous and high surface coverage with a favourable interface. In this approach, non-polar solvents (e.g. toluene or chlorobenzene) which are miscible with the perovskite precursor solution but do not dissolve the perovskite film were used for dripping. $\mathrm{PbI}_{2}$ and the mixture of MAI and FAI were used as perovskite precursors and dissolved in dimethylsulfoxide (DMSO). During the preparation of this article, Jacobsson et al. reported mixed cation (FA and MA) and anion ( $\mathrm{Br}$ and $\mathrm{I}$ ) based perovskite using a one step solvent engineering method. ${ }^{23}$ In our study only mixed cations were used with the composition $\mathrm{MA}_{x} \mathrm{FA}_{(1-x)} \mathrm{PbI}_{3}(x=0-1)$ and prepared by a one step solvent engineering method showing good air stability and less hysteresis in the case of selected compositions. An array of techniques were employed to characterize the devices in order to unravel the physical and electrical properties of the perovskite solar cells and their hysteresis behaviour.

\section{Results and discussion}

X-ray diffraction measurements were made to investigate the phase purity of mixed cation perovskite and incorporation of the FA cation into the $\mathrm{MAPbI}_{3}$ perovskite lattice. The XRD spectra were recorded for all mixed organic cation perovskites $\mathrm{MA}_{x} \mathrm{FA}_{(1-x)} \mathrm{PbI}_{3}$ $(x=0-1)$ and are shown in Fig. 1 . The perovskite film was deposited onto coarse glass as substrate and was subject to measurements after annealing the sample for one hour at $100{ }^{\circ} \mathrm{C}$ for $x=0.6$ to 1 and at $120{ }^{\circ} \mathrm{C}$ and $150{ }^{\circ} \mathrm{C}$ for $x=0.5$ and $x=0$ respectively. At room temperature, pure $\mathrm{MAPbI}_{3}$ has a tetragonal structure while $\mathrm{FAPbI}_{3}$ (black $\alpha$-phase) has a cubic structure due to slight rotation of lead iodide octahedra. ${ }^{10,24}$ The main diffraction peaks in pure $\mathrm{MAPbI}_{3}$, where structural changes were detected, were found at $\sim 14^{\circ}, 19.95^{\circ}, 24.41^{\circ}, 28.5^{\circ}$ and $31.9^{\circ}$ and belong to the characteristic peak of a tetragonal perovskite structure while peaks at $13.7^{\circ}$ and $27.8^{\circ}$ in pure $\mathrm{FAPbI}_{3}$ correspond to the cubic black stable phase of $\alpha-\mathrm{FAPbI}_{3}{ }^{24}$ The peak present at $12.63^{\circ}$ reflects the presence of non-converted $\mathrm{PbI}_{2}$, for which the intensity decreases in the mixed cation $(x=0-1)$ environment except in $\mathrm{MA}_{0.5} \mathrm{FA}_{0.5} \mathrm{PbI}_{3}$ perovskite which shows a strong peak of $\mathrm{PbI}_{2}$.

Fig. S1a-c (ESI $\dagger$ ) are focused on the characteristic peaks of the tetragonal structure of perovskite. The peaks at $14.17^{\circ}, 28.33^{\circ}$ and $31.9^{\circ}$ gradually shift to a lower diffraction angle $(2 \theta)$ with increasing amount of the FA cation. Mainly due to the relatively large size of the FA cation lattice expansion occurs. Instead of the appearance of separate and individual two peaks with different intensity of two cations, the slow shift in the diffraction angle indicates the presence of a mixed phase, where both cations were incorporated in the same lattice.

On closer visualization of the characteristic tetragonal peak at $14^{\circ}$, a high intense and narrow peak was observed in the case

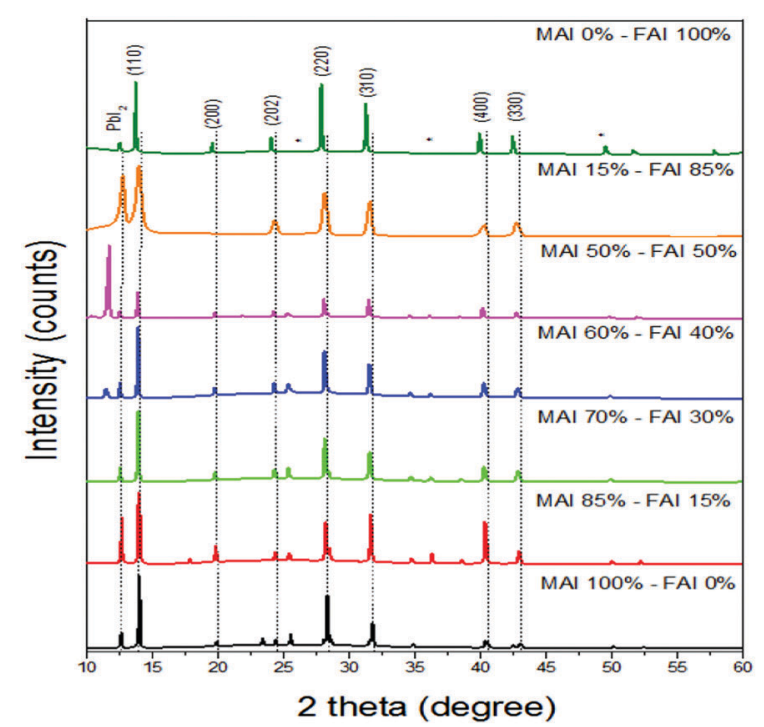

Fig. $1 \mathrm{X}$-ray diffraction spectra for the $\mathrm{MA}_{x} \mathrm{FA}_{(1-x)} \mathrm{Pbl}_{3}$ perovskite film, where $x=0,0.15,0.5,0.6,0.7,0.85,1$. These films were annealed for one hour at $100{ }^{\circ} \mathrm{C}$ for $x=0.6$ to 1 , at $120{ }^{\circ} \mathrm{C}$ for $x=0.5$ while at $150{ }^{\circ} \mathrm{C}$ for $x=0$ and 0.15 . A closer view of the characteristic peaks at $14.17^{\circ}, 28.33^{\circ}$ and $31.9^{\circ}$ is shown in Fig. S1 (ESI†). 
of $\mathrm{MAPbI}_{3}$, which suggests its larger crystallite size than mixed cation perovskite. Fig. S2 (ESI $\dagger$ ) represents the calculated average crystallite size calculated by using XRD software versus FA composition. The intensity of the peak decreases with increasing amount of FA in $\mathrm{MA}_{x} \mathrm{FA}_{(1-x)} \mathrm{PbI}_{3}(x=0-1)$ while the full width at half maximum (FWHM) increases up to $x=0.85$ in $\mathrm{MA}_{x} \mathrm{FA}_{(1-x)} \mathrm{PbI}_{3}$, while in the case of $x=0.5$ it decreases. The decrease in FWHM indicates an increase of X-ray crystallite size. For pure $\mathrm{FAPbI}_{3}$, the FWHM was found to be the highest (Fig. S1a, ESI $\dagger$ ).

In mixed cation perovskite, $\mathrm{MA}_{x} \mathrm{FA}_{(1-x)} \mathrm{PbI}_{3}(x=0.85-0.6)$, no characteristic diffraction peak of $\delta$-phase of $\mathrm{FAPbI}_{3}$ was observed (which is a photo-inactive phase) except in $x=0.5$, where the high intense peak at $11.7^{\circ}$ represents the $\delta$-phase of $\mathrm{FAPbI}_{3} \cdot{ }^{20,25}$ It is well known that the annealing temperature of the perovskite affects its final structure and its electro-optical properties. In pure methylammonium iodide (MAI) conversion to perovskite takes place between 80 and $100{ }^{\circ} \mathrm{C}$ while in the case of formamidinium black $\alpha$-phase perovskite is formed at $135-150{ }^{\circ} \mathrm{C}^{26,27}$ It is worth mentioning that $\delta$-phase of formamidinium is present only in a 50:50 ratio, which might be due to the high annealing temperature required to convert into black $\alpha$-phase of $\mathrm{FAPbI}_{3}$. Due to the higher amount of $\mathrm{FAPbI}_{3}$ in $\mathrm{MA}_{0.5} \mathrm{FA}_{0.5} \mathrm{PbI}_{3}$, these crystals are not confined in the mesoporous scaffold which limits the crystallite size to $\sim 50 \mathrm{~nm}$; therefore these crystals randomly arrange themselves on the surface of the mesoporous scaffold rather than infiltrating inside and thus form large crystallites. ${ }^{10}$ Bein et al. ${ }^{20}$ studied the stabilization of the trigonal high-temperature phase of formamidinium lead iodide. It was shown that the crystal structure of MA degrades at $125{ }^{\circ} \mathrm{C}$; however black $\alpha$-phase formed at a higher temperature $\left(135^{\circ} \mathrm{C}\right)$. Therefore we assume that, annealing temperature plays an important role in the preparation of mixed organic cation perovskites. In order to reveal the optimal annealing temperature in the case of $\mathrm{MA}_{0.5} \mathrm{FA}_{0.5} \mathrm{PbI}_{3}$, it was heated at different temperatures $\left(120^{\circ} \mathrm{C}, 135{ }^{\circ} \mathrm{C}\right.$ and $\left.150{ }^{\circ} \mathrm{C}\right)$ and subjected to X-ray diffraction and absorption spectra measurements (Fig. S3 and S4, ESI $\dagger$ ). From XRD (Fig. S3, ESI $\dagger$ ), it can be seen that at $120{ }^{\circ} \mathrm{C}$, the strong peak present at $\sim 14^{\circ}$ corresponds to the tetragonal structure of $\mathrm{MAPbI}_{3}$ along with the strong peak at $\sim 12^{\circ}$ indicating that $\mathrm{PbI}_{2}$ is not fully converted to perovskite. On increasing the temperature to $135{ }^{\circ} \mathrm{C}$, the peak at $\sim 14^{\circ}$ becomes less intense which finally disappears when the annealing temperature reaches $150{ }^{\circ} \mathrm{C}$ indicating degradation of the $\mathrm{MAPbI}_{3}$ phase. At $135{ }^{\circ} \mathrm{C}$ and $150{ }^{\circ} \mathrm{C}$, the emergence of the peak at $\sim 11^{\circ}$ confirms the presence of $\delta$-phase of $\mathrm{FAPbI}_{3}$ and the peak corresponding to $\mathrm{PbI}_{2}$ becomes more intense at this stage. The inadequate conversion into perovskite phase indicates the presence of a thermodynamically stable point beyond which the substitution of FA does not occur. ${ }^{10}$ The presence of yellow $\delta$-phase of $\mathrm{FAPbI}_{3}$ as observed in XRD also coincides with the SEM images of the perovskite shown in ESI $\dagger$ (Fig. S5). The appearance of white crystals on the surface can be observed at $135{ }^{\circ} \mathrm{C}$ and it increases on increasing the temperature to $150{ }^{\circ} \mathrm{C}$. Recently similar observations were reported..$^{10,20}$ This may be assigned to the preferred yellow phase of $\mathrm{FAPbI}_{3}$ at room temperature.
However, in absorption measurements (Fig. S4, ESI $\dagger$ ), we did not observe any significant changes except that the absorbance intensity of $\mathrm{MA}_{0.5} \mathrm{FA}_{0.5} \mathrm{PbI}_{3}$ decreases in the case of samples annealed at $135{ }^{\circ} \mathrm{C}$ and $150{ }^{\circ} \mathrm{C}$, which might be due to the conversion of $\delta$-phase yellow perovskite. In our conditions we found that the optimal annealing temperature for this ratio was $120{ }^{\circ} \mathrm{C}$ (Fig. S3, ESI $\dagger$ ), to avoid the degradation of MA cations in the matrix. Nevertheless, the geometry of the crystals depend on the mixed cation perovskite ratio to dictate the final performance of the PSCs. ${ }^{25}$

The conversion of the precursors into perovskite can be observed by absorption spectra of mixed organic cation perovskite. Perovskite films were deposited onto the mesoporous $\mathrm{TiO}_{2}$ layer to mimic the crystal growth as in devices. Fig. 2 shows the absorption spectra of mixed cation perovskite measured using an integrating sphere for all different compositions. A systematic shift of the absorption band edge to longer wavelengths was observed with increasing amount of the FA cation in the $\mathrm{MA}_{x} \mathrm{FA}_{(1-x)} \mathrm{PbI}_{3}$, where $x=0$ to 1 . The addition of the FA cation red shifts the absorption onset from $780 \mathrm{~nm}$ in pure $\mathrm{MAPbI}_{3}$ to $815 \mathrm{~nm}$ in the case of pure $\mathrm{FAPbI}_{3}$. Thus the energy band gap $\left(E_{\mathrm{g}}\right)$ can be easily tuned by varying the mixed cation ratio. For mixed cation perovskite with $x=0.5$ and pure $\mathrm{FAPbI}_{3}$, the absorbance decreases with increasing wavelength compared to other compositions.

Maximum absorbance was observed for $\mathrm{MA}_{0.6} \mathrm{FA}_{0.4} \mathrm{PbI}_{3}$ perovskite, with red-shift of the absorption onset. Fig. 3 shows the linear dependence of the optical band gap on added FA cation composition in the $\mathrm{MA}_{x} \mathrm{FA}_{(1-x)} \mathrm{PbI}_{3}$ perovskite, where $x=0$ to 1 . As the amount of the FA cation is increased in the $\mathrm{MAPbI}_{3}$ lattice, the band gap decreases from $1.59 \mathrm{eV}$ (pure $\mathrm{MAPbI}_{3}$ ) to $1.5 \mathrm{eV}$ for pure $\mathrm{FAPbI}_{3}$, while the mixed cations show an intermediate value. It is to be mentioned that these perovskite films were prepared on mesoporous $\mathrm{TiO}_{2}$; thus due to perovskite confinement in the mesoporous scaffold, it may affect the crystal structure of perovskite and thus its band gap. ${ }^{21,28}$

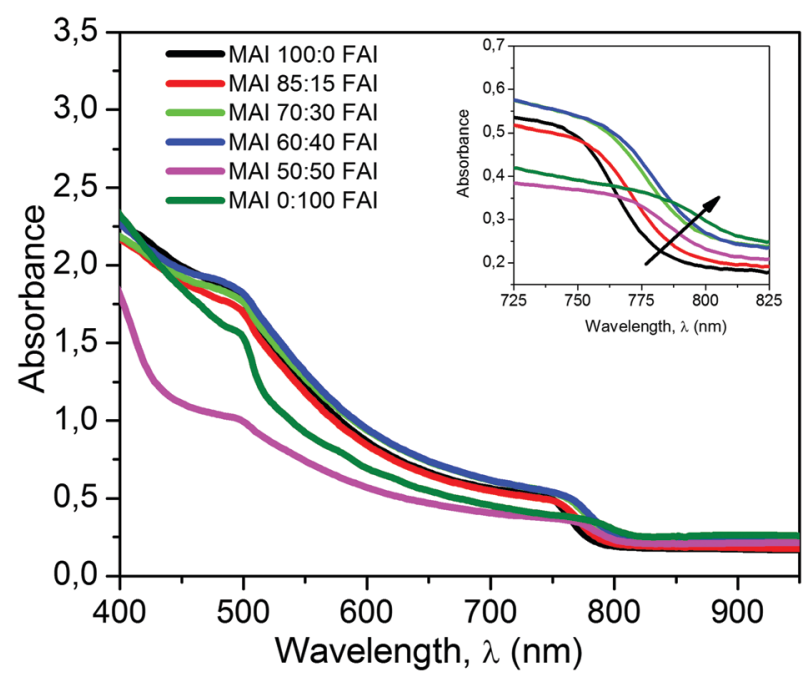

Fig. 2 UV-vis absorbance spectra of a perovskite $(\mathrm{MA})_{x}(\mathrm{FA})_{1-x} \mathrm{Pbl}_{3}$ layer on FTO including compact and mesoporous $\mathrm{TiO}_{2}$. 


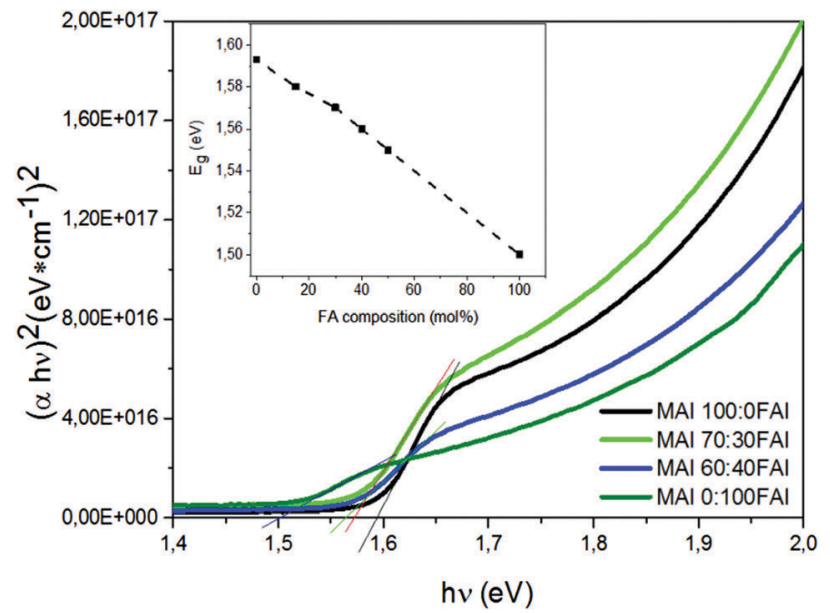

Fig. 3 Tauc plots for perovskite $(\mathrm{MA})_{x}(\mathrm{FA})_{1-x} \mathrm{Pbl}_{3}(x=0,0.6,0.7,1)$ and the inset shows the band gap (eV) for all compositions ( $x=0,0.5,0.6,0.7,0.85,1)$ plotted versus amount of formamidinium added in molar percentage.

For calculating the optical band gap, the absorption coefficient $(\alpha)$ was calculated by measuring total transmittance and reflectance spectra using an integrating sphere. Then the Tauc plot method was applied to estimate the direct band gap, i.e. linear extrapolation of the $(\alpha h \nu)^{2} v s$. $h \nu$ curve to intercept the horizontal energy axis as shown in Fig. 3.

An optimal ratio exists which offers a compromise between absorption shift and perovskite crystal quality, and will be explained in the following sections. The morphologies of the mixed perovskites were characterized by scanning electron microscopy (SEM) and scanning force microscopy (SFM) in order to visualize the crystallization process and distribution of grains in different compositions of MAI:FAI. The perovskite film was deposited atop a mesoporous layer to reproduce similar crystal growth as in devices. Fig. 4 shows the surface microstructure of pure $\mathrm{MAPbI}_{3}, \mathrm{FAPbI}_{3}, \mathrm{MA}_{0.6} \mathrm{FA}_{0.4} \mathrm{PbI}_{3}$ and the cross sectional image of the $\mathrm{MA}_{0.6} \mathrm{FA}_{0.4} \mathrm{PbI}_{3}$ perovskite based device.

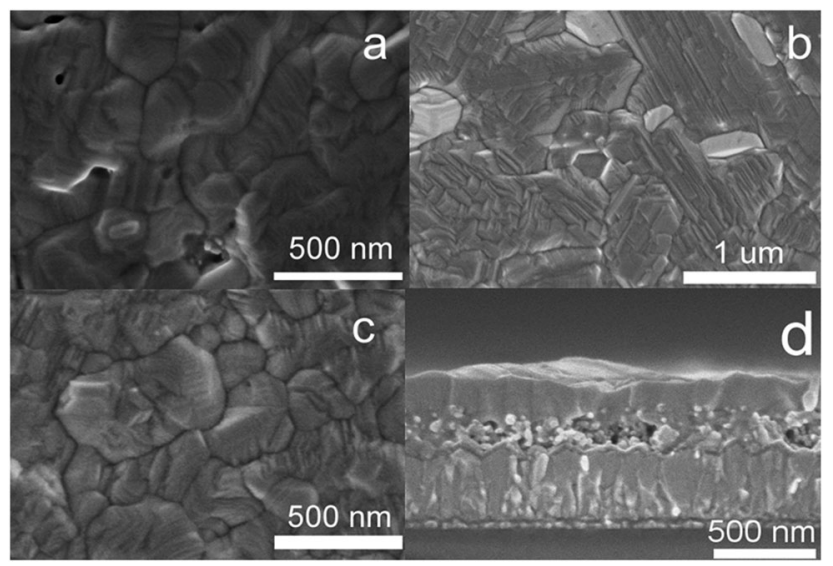

Fig. 4 (a-c) SEM images of different organic cation ratio perovskite films $\left(\mathrm{MAPbl}_{3}, \mathrm{FAPb}_{3}\right.$ and $\mathrm{MA}_{0.6} \mathrm{FA}_{0.4} \mathrm{Pbl}_{3}$ respectively) and (d) cross section image of the $\mathrm{TiO}_{2} / \mathrm{MA}_{0.6} \mathrm{FA}_{0.4} \mathrm{Pbl}_{3} /$ Spiro-OMeTAD solar cell. Panels a-c reveal the morphological evolution of the perovskite films when the organic cation composition was changed.
Fig. S5 and S6 (ESI $\dagger$ ) represent SEM images of the remaining composition. The morphology of the perovskite significantly changes with the inclusion of the FA cation. SEM images depict adequate surface coverage and densely packed grains with a less number of pinholes. In the case of $\mathrm{FAPbI}_{3}$, crystal edges were observed which led to the formation of lamellar structures. Furthermore the grain size varied with the MA:FA composition in perovskite. The crystallite size was larger in the case of pure $\mathrm{MAPbI}_{3}$ and $\mathrm{FAPbI}_{3}$ perovskite as confirmed by XRD measurements showing a narrow peak. Smaller, compact, regular and ordered crystallites with preferential orientation were observed with an average crystallite size ranging from 60 to $62 \mathrm{~nm}$ (Fig. S2, $\mathrm{ESI} \dagger$ ) in the case of $x=0.7$ and 0.6 and in close agreement with the literature value. ${ }^{29}$ These crystallites are much smaller than those observed by SEM indicating that these crystals are composed of several small grains. It is reported that during the crystallization process, if there is no lattice strain in the structure, it leads to the formation of large crystals due to more relaxation in the crystal lattice ${ }^{30,31}$ as shown in XRD measurements where the peak shifted to a lower angle with increasing amount of the FA cation. Pure $\mathrm{MAPbI}_{3}, \mathrm{FAPbI}_{3}$ and $\mathrm{MA}_{0.85} \mathrm{FA}_{0.15} \mathrm{PbI}_{3}$ show larger crystallite size as calculated by XRD measurements.

As the amount of FAI increases in the $\mathrm{MAPbI}_{3}$ lattice, the lattice strain increases due to the comparatively larger cation size of FA and crystallization slows down and consequently, small crystals were formed in the case of $x=0.7$ and $0.6(60-62 \mathrm{~nm})$ and confined in the pores of the mesoporous scaffold with preferential orientation and a high degree of order. ${ }^{32}$ The improved and controlled crystallization of the perovskite film may reduce the density of defects and the quality of perovskite crystals can affect the charge carrier diffusion length, efficiency of charge dissociation and transport. ${ }^{33-45}$ Subsequently, this will influence the performance of the devices as the presence of defects creates the trapping site for recombination of electrons and holes. Therefore the larger crystals at the interface are beneficial owing to a reduction of grain boundaries and trap sites and they also act as scattering centers for the incoming light and increase the effective optical path length of light in the device.

Notably, in some of the perovskite compositions, more specifically, in $\mathrm{MA}_{0.5} \mathrm{FA}_{0.5} \mathrm{PbI}_{3}$ and pure $\mathrm{FAPbI}_{3}$, individual grains exhibit higher brightness compared with the adjacent area. Fig. S3 (ESI $\dagger$ ) shows the SEM images of $\mathrm{MA}_{0.5} \mathrm{FA}_{0.5} \mathrm{PbI}_{3}$ with different annealing temperature. It can be observed that bright contrast was present in all the perovskite samples annealed at different temperature. In all likelihood, this could have possibly originated due to the non-perovskite $\delta$-phase of $\mathrm{FAPbI}_{3}$, which was also confirmed by the XRD measurement made at different annealing temperature.

We observed that the $\mathrm{MA}_{0.6} \mathrm{FA}_{0.4} \mathrm{PbI}_{3}$ ratio shows almost negligible hysteresis in $J-V$ measurements. In such samples we investigated the role of annealing temperature on perovskite film morphology and its crystal formation by means of in-situ SFM as the samples are sensitive to humidity. ${ }^{46,47}$ Pure methyl ammonium iodide (MAI) at room temperature forms an active $\beta$-phase. At around $55-60{ }^{\circ} \mathrm{C}$, this active $\beta$-phase is converted into $\alpha-\mathrm{CH}_{3} \mathrm{NH}_{3} \mathrm{PbI}_{3}$. At the initial stage, i.e. prior to annealing, the 


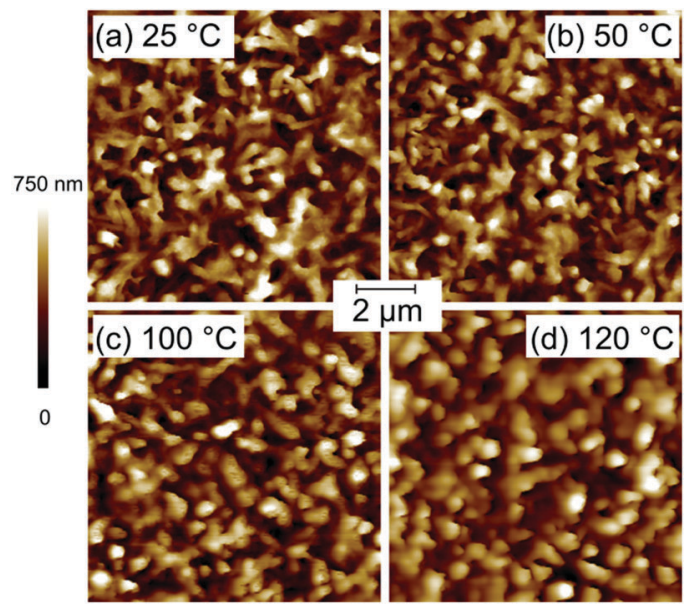

Fig. 5 SFM topographic images of $\mathrm{FTO} / \mathrm{MA}_{0.6} \mathrm{FA}_{0.4} \mathrm{Pbl}_{3}$, during in situ temperature annealing. The images were recorded at (a) 25, (b) 50, (c) 100 and (d) $120{ }^{\circ} \mathrm{C}$. At each temperature we waited 20 minutes to allow the sample to thermally equilibrate.

deposited layer formed a surface with a root-mean-square $(\mathrm{rms})$ roughness of $147 \mathrm{~nm}$ at a $10 \times 10 \mu \mathrm{m}^{2}$ scale. The deposited layer showed a 3-dimensional network like structure (Fig. 5a).

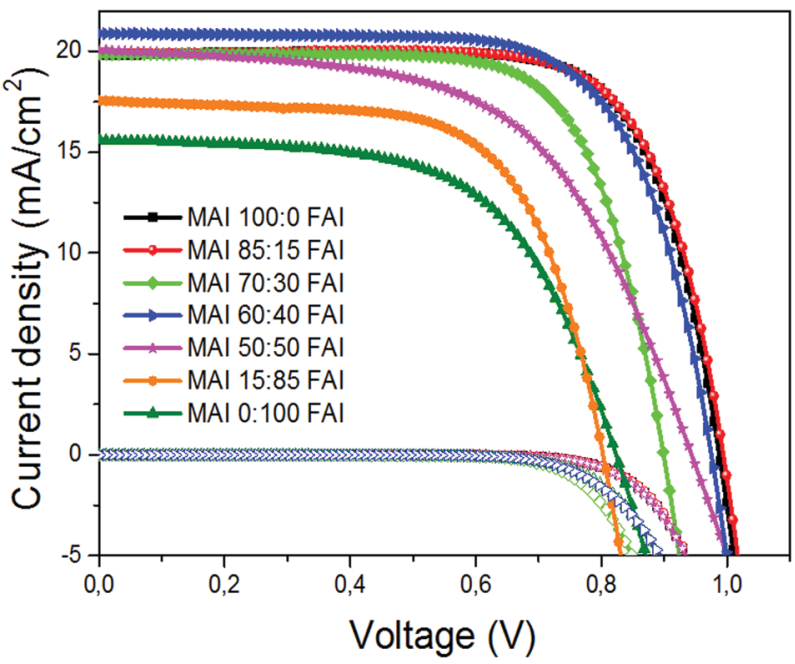

Fig. $6 \mathrm{~J}-V$ characteristics for mesoscopic devices with mixed cation perovskite $\mathrm{MA}_{x} \mathrm{FA}_{(1-x)} \mathrm{Pbl}_{3}$ (where $x=0,0.5,0.6,0.7,0.85,1$ ) as a light absorber.
On increasing the temperature to $50{ }^{\circ} \mathrm{C}$ we observed closing of small pores, and we attribute this to the intercalation induced volume expansion of inorganic materials in the organic phase. Upon further increasing the annealing temperature to $100{ }^{\circ} \mathrm{C}$ and $120^{\circ} \mathrm{C}$ slight changes in morphology were observed (Fig. 5c and d). These microstructural changes reflect the conversion of the deposited layer into the perovskite structure, which is very prominent at or above $100{ }^{\circ} \mathrm{C}$.

\section{Photovoltaic properties}

To calculate the figure of merit for the fabricated PV devices, the $J-V$ curves were recorded in the dark and under simulated air mass 1.5 global (AM1.5G) sunlight. Fig. 6 shows the $J-V$ characteristics in the dark and under illumination $\left(100 \mathrm{~mW} \mathrm{~cm}^{-2}\right)$ for the best performing devices from $V_{\mathrm{oc}}$ to $J_{\mathrm{sc}}$ at $100 \mathrm{mV} \mathrm{s}^{-1}$. Table 1 summarizes the average PV parameters with standard deviation along with the best-performing devices prepared for different compositions of MAI:FAI together with series and shunt resistance. An increase in short circuit current $\left(J_{\text {sc }}\right)$ after the inclusion of $\mathrm{FA}$ in $\mathrm{MA}_{x} \mathrm{FA}_{(1-x)} \mathrm{PbI}_{3}$ perovskite can be observed, which was expected due to the shift of the absorption onset to a longer wavelength. The average $J_{\mathrm{sc}}$ and fill factor $(\mathrm{FF})$ increased gradually from 19.57 to $21 \mathrm{~mA} \mathrm{~cm}{ }^{-2}$ and from 64.8 to $70 \%$ respectively with increasing FA concentration from 0 to $40 \mathrm{~mol} \%$. The lowest value of $J_{\text {sc }}$ was observed for $\mathrm{MA}_{0.5} \mathrm{FA}_{0.5} \mathrm{PbI}_{3}, \mathrm{MA}_{0.15} \mathrm{FA}_{0.85} \mathrm{PbI}_{3}$ and pure $\mathrm{FAPbI}_{3}$, which coincides with the optical absorption of these perovskite materials (Fig. 2). A drop in $V_{\mathrm{oc}}$ was observed on increasing the concentration of FA beyond $40 \%$, for pure $\mathrm{MAPbI}_{3} V_{\text {oc }}$ of $950 \mathrm{mV}$ was obtained, while the lowest $V_{\mathrm{oc}}$ was obtained in the case of pure $\mathrm{FAPbI}_{3}\left(V_{\mathrm{oc}}=750 \mathrm{mV}\right)$. In the case of pure $\mathrm{FAPbI}_{3}$, the drop in $V_{\mathrm{oc}}$ might be due to the presence of non-perovskite $\delta$-phase which destroys the crystal lattice and crystal structure of perovskite and hence modifies the band gap. ${ }^{21,28}$ On the other hand, in the case of $\mathrm{MA}_{0.6} \mathrm{FA}_{0.4} \mathrm{PbI}_{3}$, the high value of $V_{\text {oc }}$ could be related to the better confinement of the small sized perovskite crystals in the pores of the mesoporous scaffold with preferential orientation and a high degree of order. ${ }^{32}$

Similarly, low FF was observed in the case of $\mathrm{MA}_{0.5} \mathrm{FA}_{0.5} \mathrm{PbI}_{3}$, $\mathrm{MA}_{0.15} \mathrm{FA}_{0.85} \mathrm{PbI}_{3}$ and pure $\mathrm{FAPbI}_{3}$, due to the presence of yellow $\delta$-phase of $\mathrm{FAPbI}_{3}$ causing a sudden drop in $\mathrm{PV}$ performance. This feature can be related to the increase in series resistance and the decrease in shunt resistance (Fig. S8, ESI $\dagger$ ). The series and shunt resistance values were evaluated using the software

Table 1 Average photovoltaic parameters and calculated hysteresis index $(\mathrm{HI})$ of the devices under $100 \mathrm{~mW} \mathrm{~cm}^{-2}$. The scan direction was from $V_{\text {oc }}$ to $J_{\mathrm{sc}}$. The values in parentheses are reported for the best devices

\begin{tabular}{|c|c|c|c|c|c|c|c|c|}
\hline $\begin{array}{l}\text { Organic } \\
\text { cation ratio }\end{array}$ & $\begin{array}{l}\text { Annealing } \\
T\left({ }^{\circ} \mathrm{C}\right)\end{array}$ & 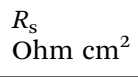 & 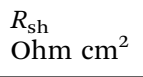 & $J_{\mathrm{sc}}\left(\mathrm{mA} \mathrm{cm}^{-2}\right)$ & $V_{\mathrm{oc}}(\mathrm{V})$ & $\mathrm{FF}(\%)$ & PCE (\%) & HI \\
\hline MAI 100: FAI 0 & 100 & 5.10 & 1487.48 & $19.57 \pm 0.74$ (19.79) & $0.95 \pm 0.03(0.987)$ & $64.79 \pm 6.37(74.18)$ & $12.11 \pm 0.97(14.49)$ & 0.16 \\
\hline MAI 85 : FAI 15 & 100 & 4.93 & 7947.37 & $19.78 \pm 0.07(19.90)$ & $0.97 \pm 0.01(0.994)$ & $70.61 \pm 1.69(73.32)$ & $13.62 \pm 0.42(14.50)$ & 0.10 \\
\hline MAI 70 : FAI 30 & 100 & 5.40 & 9033.63 & $19.69 \pm 0.36(19.84)$ & $0.89 \pm 0.01(0.899)$ & $66.63 \pm 3.21(71.39)$ & $11.85 \pm 0.58(12.73)$ & 0.05 \\
\hline MAI 60 : FAI 40 & 100 & 5.25 & 3738.2 & $20.99 \pm 0.32(20.87)$ & $0.983 \pm 0.01(0.975)$ & $69.26 \pm 1.17(69.97)$ & $14.30 \pm 0.49(14.23)$ & 0.005 \\
\hline MAI 50 : FAI 50 & 120 & 12.62 & 591.60 & $16.64 \pm 2.36(19.92)$ & $0.86 \pm 0.02(0.929)$ & $56.77 \pm 6.33(54.99)$ & $8.16 \pm 1.54(10.18)$ & 0.28 \\
\hline MAI 15 : FAI 85 & 150 & 6.18 & 882.08 & 17.55 & 0.802 & 65.5 & 9.22 & 0.12 \\
\hline MAI 0 : FAI 100 & 150 & 10.50 & 1461.65 & $13.91 \pm 1.60(15.66)$ & $0.75 \pm 0.02(0.805)$ & $52.01 \pm 2.95(59.80)$ & $5.42 \pm 1.00(7.53)$ & 0.20 \\
\hline
\end{tabular}


from the slope of the $J-V$ curve and are reported in Table 1 . We observed a decrease in series resistance, while an increase in shunt resistance for up to $40 \mathrm{~mol} \%$ of FA cation, this can be related to the increased grain size of the perovskite and better confinement of perovskite inside the pores for intimate connectivity with the $\mathrm{TiO}_{2}$ layer. ${ }^{9}$

The grain size increases with the inclusion of $\mathrm{FAPbI}_{3}$, but also decreases up to a certain concentration of FAI (40 mol\%, $x=0.6$ ) and beyond that concentration, the grain size again increased for $\mathrm{MA}_{0.5} \mathrm{FA}_{0.5} \mathrm{PbI}_{3}$ and pure $\mathrm{FAPbI}_{3}(x=0.5$ and 0$)$ as supported by the XRD and SEM studies. Changes in series and shunt resistance values are correlated with the morphological changes in mixed perovskite after inclusion of $\mathrm{FAPbI}_{3}$. It is reported that the large-sized grain reduces the grain boundaries and thus series resistance might decrease. Similarly, the decrease in shunt resistance might be a result of the shunting pathway created due to the inadequate connectivity between the blocking layer and the perovskite interface. The decreased $V_{\mathrm{oc}}$ and low FF point towards high charge recombination losses (low shunt resistance and high series resistance) in the case of $x=0.5-0 .{ }^{48}$ Pure $\mathrm{MAPbI}_{3}$ based devices gave good performance; however, they suffered from hysteresis behaviour (Table S1, ESI $\dagger$ ). It can be deduced from Fig. 6 that there is an improvement in the average PCE in the case of mixed perovskite compared to pure MAI $(\eta=12.11 \pm 0.97 \%)$ or pure FAI $(5.42 \pm 1.00 \%)$. An improvement in PCE was achieved for $\mathrm{MA}_{0.85} \mathrm{FA}_{0.15} \mathrm{PbI}_{3}(\eta=13.62 \pm 0.42 \%)$; however $\mathrm{MA}_{0.6} \mathrm{FA}_{0.4} \mathrm{PbI}_{3}$ gave the best $\mathrm{PV}$ performance.

One of the main concerns in perovskite solar cell behavior is the presence of hysteresis in the current-voltage curve depending on the measurement direction (forward or reverse) and scan rate. ${ }^{49-51}$

$J-V$ curves were measured at various scan rates for both reverse and forward directions at different dwell time and we found that in our case, $100 \mathrm{mV} \mathrm{s}^{-1}$ was the optimized scan rate.

The hysteresis effect has been quantified as a hysteresis index as reported by Kim et al. (Table S1, ESI $\dagger$ ). To calculate the degree of hysteresis (Fig. S7, ESI $\dagger$ ) and the PV parameters and $\mathrm{HI}$ are presented in Table S1 (ESI $\dagger$ ). The hysteresis index can be lowered by increasing the FAI ratio. It was found that the degree of hysteresis decreases with increasing amount of FAI up to $40 \mathrm{~mol} \%$. Beyond this composition, the degree of hysteresis increases.

A rational match can be obtained for $\mathrm{MA}_{0.6} \mathrm{FA}_{0.4} \mathrm{PbI}_{3}$, where the PCE is the best with a negligible degree of hysteresis. The lowest series resistance was noticed in $\mathrm{MA}_{0.85} \mathrm{FA}_{0.15} \mathrm{PbI}_{3}$ which is justified by its high FF and performance. Hysteresis behaviour in PSCs is generally associated with high capacitance (on the order of $\mathrm{mF} \mathrm{cm} \mathrm{cm}^{-2}$ ) compared to Si cells (on the order of $\mu \mathrm{F} \mathrm{cm}{ }^{-2}$ ). ${ }^{52}$ This capacitance effect was attributed by some authors to (i) the ferroelectricity or polarization of the perovskite layer; (ii) contact conductivity; (iii) diffusion of excess ions as interstitial defects; and/or (iv) trapping/de-trapping of charge carriers.

Even though recent studies have pointed ion migration $\left(\mathrm{I}^{-}\right.$and $\mathrm{MA}^{+}$) and charge trapping at the interface as a presumptive cause of hysteresis in perovskite solar cells, the mechanism of ion transportation and origin of these traps are still scarcely understood. ${ }^{51,53}$ Recently, reports on the generation of ion migration channels ${ }^{54}$ were reported. One of them is the local lattice distortion due to confinement in the mesoporous scaffold. Mostly $70 \%$ of pure $\mathrm{MAPbI}_{3}$ within the mesoporous scaffold was found to be disordered with more lattice defects, which is undetectable in XRD measurements. ${ }^{55}$ This may explain severe photocurrent hysteresis in mesoporous devices in addition to the trapping effect. In our case, the calculated crystallite size was the least in the case of $x=0.6$ and 0.7 (60-62 nm) which shows better confinement in the scaffold and probably preferred orientation with less distortion in the lattice and thus experiencing negligible hysteresis. However in the case of larger crystal size in the remaining compositions studied here, a comparatively high degree of hysteresis was observed. However, the local rearrangement of charges at the interfaces or in defects in the perovskite layer could give rise to the reported capacitive effects, while the existence of ionic vacancies is influenced by the process adopted for crystal growth. ${ }^{54}$

To elucidate the device performance, we measured the devices at different scan rates in both the forward and reverse direction and almost negligible hysteresis could be identified in some devices. In other words, the hysteresis behaviour could be controlled by finding an appropriate ratio due to optimal crystal formation as well as reduction of trap sites. Fig. S7 (ESI $\dagger$ ) shows current densityvoltage $(J-V)$ curves in the reverse and forward direction to see the hysteresis depending on the organic cation ratio. The shape of the crystals and the direction of crystal growth induce the creation of trap states in the perovskite structure. ${ }^{25,56}$ In accordance with the absorbance measurements, the inclusion of formamidinium cation results in shifting of the incident photon-to-current efficiencies (IPCE) onset towards longer wavelength (inset Fig. 7). By increasing the FAI concentration, it is expected to absorb more light in the near IR part of the spectrum, which can be deduced from the IPCE graph (inset Fig. 7). ${ }^{14}$

For all the compositions studied here, except pure $\mathrm{FAPbI}_{3}$, ca. $80-85 \%$ light to electricity conversion can be observed in the visible part of the spectra. The incident photon-to-current efficiency (IPCE) spectra were recorded in the wavelength range of

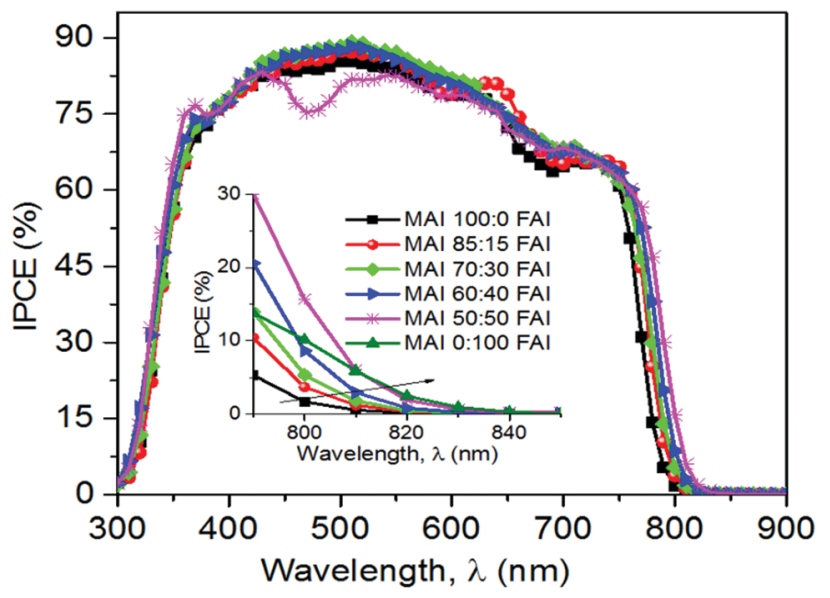

Fig. 7 Incident photon-to-current efficiency of the devices. Inset shows the closer view of the shifting of IPCE onset towards longer wavelength with increasing amount of the FA cation in $\mathrm{MA}_{x} \mathrm{FA}_{(1-x)} \mathrm{Pbl}_{3}$ perovskite film, where $(x=0$ to 1$)$. 
300-850 nm, where the PSCs showed photon-to-current conversion. This indicates that excitons and/or free charges were effectively generated in the perovskite layers upon light illumination. In the case of pure $\mathrm{FAPbI}_{3}$, the rapid degradation of devices did not permit the measurement of good IPCE spectra.

\section{Impedance measurements}

To understand the correlation between charge carrier extraction dynamics and crystallographic properties of perovskite films, we performed impedance spectroscopy (IS) which provides information concerning the performance of PSCs at different charge-carrier densities. ${ }^{57}$ Previous reports suggest that the device architecture and particularly the perovskite layer play an important role in the interpretation of the impedance response. ${ }^{58}$ Thus, to study the charge dynamics of the different layers in the devices, samples were analysed from maximum power point voltage to lower voltage. The measurements were performed by varying the illumination intensity under $V_{\mathrm{oc}}$ conditions. On increasing light intensity, the charge carrier concentration increases and an increase in $V_{\mathrm{oc}}$ was obtained. An equivalent circuit used for the fitting $^{60}$ of impedance measurements is shown in Fig. S9 (ESI $\dagger$ ).

As reported, the hysteresis behaviour of the device is linked to the dielectric properties of the perovskite material. ${ }^{59}$

Device capacitance is an important parameter to explain the mechanisms which control undesired effects such as hysteresis behaviour. ${ }^{61}$ Recently, Bisquert ${ }^{62}$ reported how the acceptance or release of additional charges has repercussions on capacitance due to the change in the Fermi level of the system. The authors found that capacitance is independent of voltage for both interfaces (perovskite/ $\mathrm{TiO}_{2}$ or perovskite/Spiro-OMeTAD) but is dependent on the perovskite layer itself. Capacitance reflects the density of states (DOS) of a material, and thus a high capacitance value in perovskite shows a high DOS. Fig. 8 illustrates the value of capacitance for different organic cation compositions in PSCs.

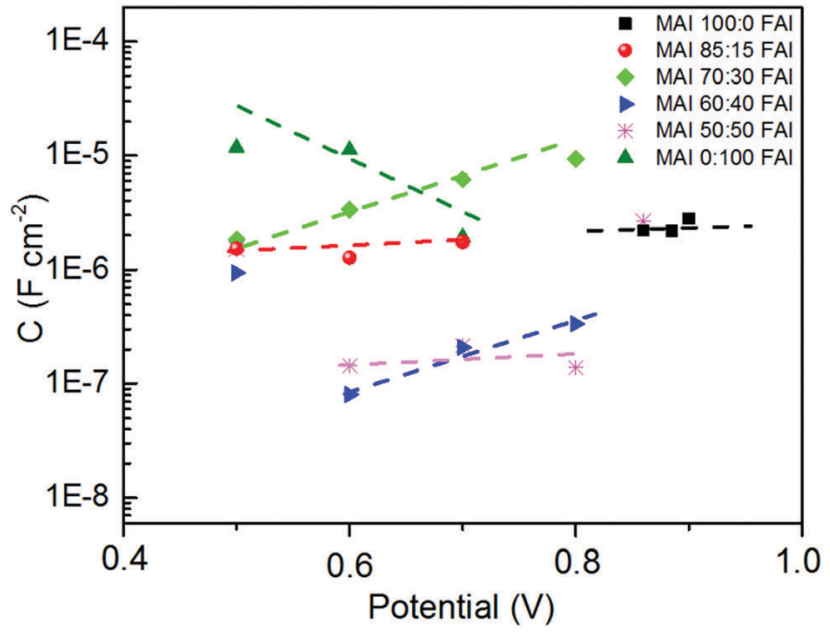

Fig. 8 Capacitance values for $\mathrm{MA}_{x} \mathrm{FA}_{(1-x)} \mathrm{Pbl}_{3}$. Dash lines serve as a visual aid only. Impedance measurements were performed at open-circuit in the 2-50 $\mathrm{MHz}$ frequency range. The equivalent circuit used and the typical impedance spectra are shown in Fig. S8 (ESI $\dagger)$.
The capacitance is almost independent of the applied voltage, and depending on the ratio, they possess different capacitance values. Here also, the 60:40 ratio shows the lowest capacitance value, which is in agreement with the lowest hysteresis. As it is well known, the semicircle observed in the impedance spectra is related with the diffusion-recombination process. In all cases, the magnitude of the impedance response generally increases with a decrease in the applied voltage. This trend is due to the fact that an increase of voltage entails a reduction of the recombination resistance, and therefore the size of the semicircle. The Nyquist plot (Fig. S10, ESI $\dagger$ ) shows the existence of a unique semicircle or two depending on the perovskite. It has been reported that the distinct impedance features may originate from the distribution of trapping states within the perovskite band gap due to the inclusion of formamidinium cations in the structure.

\section{Stability}

The low stability of perovskite based solar cells under high moisture is the current bottleneck to upscale this technology. In general, the critical step in the fabrication of the devices is the perovskite layer deposition. A perovskite film deposited under controlled conditions exhibits good pinhole-free film coverage; additionally some researchers have reported that a small percentage (less than $30 \%$ ) of humidity during the fabrication process could be beneficial to accelerate the growth of perovskite crystals in order to obtain a homogeneous film. ${ }^{63-65}$ Mainly, this instability is based on the facile phase transitions at room temperature and formation of hydrated phases owing to its hydrophilic character. The FA cation exhibits lower stability than MA; however the presence of the smaller MA cation in mixed perovskite with FA improves stability even in high humidity conditions, which could be attributed to ten times higher dipole moment of the small sized MA cation than FA. MA stabilizes the 3D network of $\mathrm{PbI}_{6}$ octahedra through hydrogen bonding between the hydrogen of the ammonium moiety and iodide ions, or another possible reason for stability is the strong coulomb interaction between the MA cation and $\mathrm{PbI}_{6}$ octahedra. ${ }^{20}$

Fig. 9 represents the evolution of the solar cell parameters $V_{\mathrm{oc}}, J_{\mathrm{sc}}$ and FF, PCE plotted as a function of time to evaluate the stability. The un-encapsulated devices were kept in the dark and humidity conditions $(<60 \% \mathrm{RH})$ and monitored by measuring $J-V$ characteristics. In general, the devices were found to be relatively stable, and in some cases, the device performance was found to be increased after 5 days of storage, which we assign as due to the improved intimate contact with the perovskites and HTM, or better infiltration of active materials inside the three dimensional $\mathrm{TiO}_{2}$ structure. However, in most of the cases the device performance stabilizes after 10 days and relatively uniform output can be observed. It was noted that the substitution of FA by MA induces perovskite stability. The stable value of PCE were exposed for $x=0.85$ composition, after 5 days. The calculated drop in PCE after a period of four months was only $14.41 \%$ (from $14.5 \%$ to $12.41 \%$ ). 


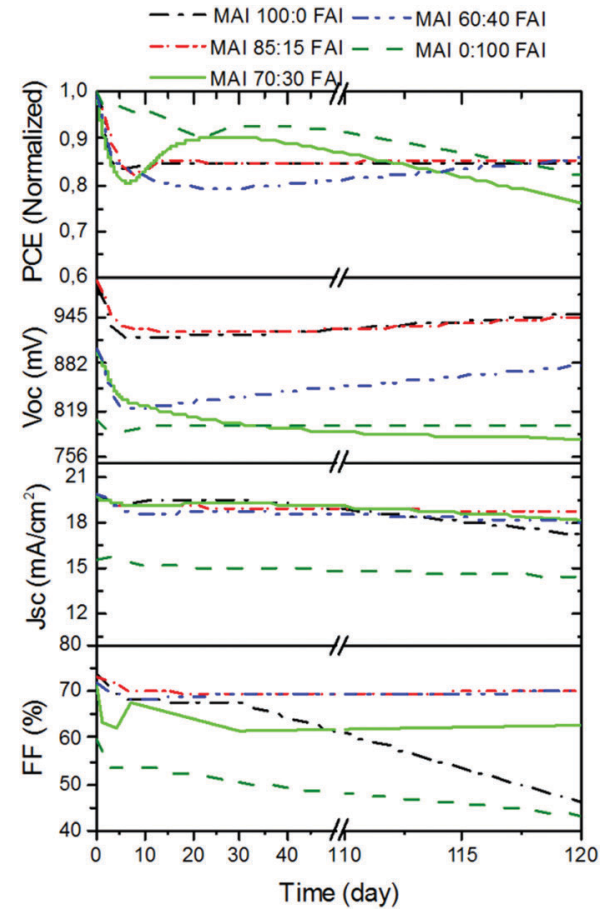

Fig. 9 Evolution of stability data for the solar cells with different organic cation ratios.

\section{Conclusions}

To summarize, we have studied varying compositions of mixedcation perovskite $\mathrm{MA}_{x} \mathrm{FA}_{1-x} \mathrm{PbI}_{3}$ (where $x=0-1$ ) for solar cell fabrication using a one step solvent engineering approach. It was found that the addition of the formamidinium cation in the MAI slows down the crystal formation in perovskites and allows the formation of large crystals and a high degree of order. Devices fabricated using pure FAI gave the lowest performance here, while all the mixed and pure MAI showed superior PV performance. The addition of $15-40 \%$ FAI in MAI was found to influence the PV performance and dramatically reduced the hysteresis behaviour. The mixed-cation perovskite $\mathrm{MA}_{0.6} \mathrm{FA}_{0.4} \mathrm{PbI}_{3}$ exhibited hysteresis free behaviour along with the best PV performance. By using the solvoneering (solvent engineering) approach, we were able to fabricate devices with $>15 \%$ photon-to-current conversion efficiency. The strategy of mixing organic ammonium compounds opens up new prospects for further optimization and understanding of hysteresis free behaviour.

\section{Experimental section}

All chemicals were procured from Sigma Aldrich and used as such. $\mathrm{PbI}_{2}$ was obtained from TCI, while MAI and FAI were procured from Dyesol and employed without any treatment or purification. $\quad 2,2^{\prime}, 7,7^{\prime}$-Tetrakis( $N, N$-di- $p$-methoxyphenyamine)9,9-spirobifluorene (Spiro-OMeTAD) was acquired from Merck KGaA.

\section{Device fabrication}

Perovskite solar cells were fabricated on FTO-coated glass (TEC15, Pilkington) patterned by laser etching. Before any deposition, the substrates were cleaned using Hellmanex solution and rinsed with deionized water and ethanol and finally ultrasonicated in 2-propanol and air dried. The $\mathrm{TiO}_{2}$ compact layer was deposited by spray pyrolysis at $450{ }^{\circ} \mathrm{C}$ using $1 \mathrm{~mL}$ of titanium diisopropoxide bis(acetyl acetonate) precursor solution (75\% in 2-propanol, Sigma Aldrich) in $19 \mathrm{~mL}$ of pure ethanol using dry air as carrier gas. After the blocking layer deposition, the substrates were kept for further 30 minutes at $450{ }^{\circ} \mathrm{C}$ for the formation of anatase phase. Once the samples were cooled down at room temperature, they were treated with $\mathrm{TiCl}_{4}$ (dipping in a $0.02 \mathrm{M} \mathrm{TiCl}_{4}$ solution in deionized water at $70{ }^{\circ} \mathrm{C}$ for 30 minutes) with the aim to obtain a homogeneous layer. Next, the samples were washed with deionized water, heated at $500{ }^{\circ} \mathrm{C}$ for 10 minutes and were cooled down to room temperature. After this, a $\mathrm{TiO}_{2}$ mesoporous layer (Dyesol, 30NRD) was deposited by spin coating (4000 rpm for $30 \mathrm{~s}$ ) and then samples were heated progressively up to $450{ }^{\circ} \mathrm{C}$ for 2 hours.

Atop this, $\mathrm{MA}_{x} \mathrm{FA}_{1-x} \mathrm{PbI}_{3}(x=0-1)$ was deposited by the one step method followed by the toluene solvoneering (solvent engineering) method. The solution and perovskite films were prepared inside an argon glove box under moisture and oxygen controlled conditions $\left(\mathrm{H}_{2} \mathrm{O}\right.$ level: $<1 \mathrm{ppm}$ and $\mathrm{O}_{2}$ level: $\left.<10 \mathrm{ppm}\right)$ and kept under stirring at $80{ }^{\circ} \mathrm{C}$ overnight in order to dissolve completely $\mathrm{PbI}_{2}$. Perovskite precursor solution composed of lead iodide $(1.25 \mathrm{M})$ $\left(\mathrm{PbI}_{2}\right)$ and a mixture of formamidinium iodide (FAI) and methyl ammonium iodide (MAI) were dissolved in dimethylsulfoxide (DMSO) and the precursor solution was spin coated on top of the mesoporous layer at $1000 \mathrm{rpm}$ for $10 \mathrm{~s}$ and then at $6000 \mathrm{rpm}$ for $30 \mathrm{~s}$. During the second step, toluene $(900 \mu \mathrm{L})$ was dripped at the centre of the substrate in the last 15 seconds. After solvent treatment, the films were transferred onto a hotplate and annealed at $100-150{ }^{\circ} \mathrm{C}$ for 60 minutes depending on the cation composition. Spiro-OMeTAD was then spun coated at $4000 \mathrm{rpm}$ for $30 \mathrm{~s}$ by dissolving $72.3 \mathrm{mg}$ of Spiro-OMeTAD in $1 \mathrm{~mL}$ of chlorobenzene; $21.9 \mu \mathrm{L}$ of tris(2-(1H-pyrazol-1-yl)-4-tert-butylpyrydine)cobalt(III) bis(trifluoromethylsulphonyl)imide (FK209) from stock solution (400 mg of FK209 in $1 \mathrm{~mL}$ of acetonitrile), $17.5 \mu \mathrm{L}$ of lithium bis(trifluoromethylsulphonyl)imide (LiTFSI) stock solution (520 mg of LiTFSI in $1 \mathrm{~mL}$ of acetonitrile) and $28.8 \mu \mathrm{L}$ of 4 -tert-butylpyridine were also added to the solution as dopants. Finally, $80 \mathrm{~nm}$ of gold $\mathrm{Au}$ ) was thermally evaporated on the top of the cell as a cathode under a vacuum level between $1 \times 10^{-6}$ and $1 \times 10^{-5}$ Torr.

\section{Characterization}

For structural characterization, thick films were prepared by spin coating of $\mathrm{MA}_{x} \mathrm{FA}_{(1-x)} \mathrm{PbI}_{3}(x=0-1)$ solutions onto coarse glass. X-ray diffractograms were recorded on a Rigaku powder diffractometer using a $\mathrm{CuK} \alpha$ source. The measurements were performed in the Bragg-Brentano geometry. The samples were mounted without any further modification and the divergence slit was adjusted to the dimension of the films. A scan range of $10^{\circ}-60^{\circ}$ was selected with an acquisition time of 1 degree per min. 
A baseline correction was applied to diffractograms to compensate for the noise arising from the substrate.

Transmittance and reflectance spectra of the perovskite films were collected using a Perkin Elmer UV-vis-NIR lambda 1050 spectrophotometer using a $160 \mathrm{~mm}$ integrating sphere. Surface morphology and cross-sectional images were obtained using a Hitachi S-4800 field emission scanning electron microscope at power $2 \mathrm{kV}$.

Current density-voltage $(J-V)$ curves were recorded with a Keithley 2400 source-measurement-unit under AM1.5G, $100 \mathrm{~mW} \mathrm{~cm}^{2}$ illumination from a certified Class AAA, $450 \mathrm{~W}$ solar simulator (ORIEL, 94023 A). Light output power was calibrated using a NREL certified calibrated mono-crystalline silicon solar cell. A black metal mask $\left(0.16 \mathrm{~cm}^{2}\right)$ was used over the square solar cell active area $\left(0.5 \mathrm{~cm}^{2}\right)$ to reduce the influence of scattered light.

Photovoltaic parameters including $J_{\mathrm{sc}}, V_{\mathrm{oc}}$, fill factor (FF), and power conversion efficiency (PCE) were extracted from the photocurrent-voltage $(J-V)$ curves of the solar cells and are listed in Table 1. The scan rate and the active area used for measuring the devices were optimized as such to calculate the real value for efficiencies without having any hysteresis effect (active area: $0.16 \mathrm{~cm}^{2}$, scan rate: $100 \mathrm{mV} \mathrm{s}^{-1}$, pre sweep delay: $20 \mathrm{~s}$ ). The IPCE measurements were performed using a Newport $150 \mathrm{~W}$ xenon lamp coupled to an Oriel Cornerstone 260 motorized $1 / 4 \mathrm{~m}$ monochromator as the light source and a 2936-R power meter to measure the short circuit current. The impedance measurements were carried under illumination in order to approach the operation conditions for solar cells. Samples were illuminated by a $530 \mathrm{~nm}$ LED (LUXEON) over a wide range of DC light intensities. Spectra were recorded with the application of a bias equal to the potential induced by the light. The bias close to $V_{\text {oc }}$ and applied during the measurements was chosen to minimize the current running through the cell during the measurements and to avoid the voltage drop due to series resistance. Z-view (Scribner) was used for equivalent circuit modelling of the EIS spectra.

SFM measurements were performed using an EnviroScope (Bruker Nano Surfaces) which allows controlling the environmental condition such as humidity, oxygen content and sample temperature. The samples were deposited on glass substrates following the procedure described above. The glass substrates were much smoother than the FTO substrates. Therefore the roughness of the perovskite layers could be measured more accurately.

\section{Acknowledgements}

This project has received funding from the European Union Seventh Framework Programme under grant agreement no. 607232 [THINFACE].

\section{Notes and references}

1 B. O'Regan and M. Grätzel, Nature, 1991, 353, 737-740.

2 A. Kojima, K. Teshima, Y. Shirai and T. Miyasaka, J. Am. Chem. Soc., 2009, 131, 6050-6051.
3 M. Grätzel, R. A. J. Janssen, D. B. Mitzi and E. H. Sargent, Nature, 2012, 488, 304-312.

4 S. Kazim, M. K. Nazeeruddin, M. Grätzel and S. Ahmad, Angew. Chem., Int. Ed., 2014, 53, 2812-2824 (Angew. Chem., 2014, 126, 2854-2867).

5 X. Liu, W. Zhao, H. Cui, Y. Xie, Y. Wang, T. Xu and F. Huang, Inorg. Chem. Front., 2015, 2, 315-335.

6 S. Brittman, G. W. P. Adhyaksa and E. C. Garnett, MRS Commun., 2015, 5, 7-26.

7 V. M. Goldschmidt, Naturwissenschaften, 1926, 14, 477-485.

8 G. E. Eperon, S. D. Stranks, C. Menelaou, M. B. Johnston, L. M. Herz and H. J. Snaith, Energy Environ. Sci., 2014, 7, 982.

9 J.-W. Lee, D.-J. Seol, A.-N. Cho and N.-G. Park, Adv. Mater., 2014, 6, 1-8.

10 G. E. Eperon, C. E. Beck and H. J. Snaith, Mater. Horiz., 2016, 3, 63-71.

11 P. Piatkowski, B. Cohen, C. S. Ponseca, M. Salado, S. Kazim, S. Ahmad, V. Sundström and A. Douhal, J. Phys. Chem. Lett., 2015, 7, 204-210.

12 V. Adinolfi, M. Yuan, R. Comin, E. S. Thibau, D. Shi, M. I. Saidaminov, P. Kanjanaboos, D. Kopilovic, S. Hoogland, Z.-H. Lu, O. M. Bakr and E. H. Sargent, Adv. Mater., 2016, 28, 3406-3410.

13 A. A. Zhumekenov, M. I. Saidaminov, M. A. Haque, E. Alarousu, S. P. Sarmah, B. Murali, I. Dursun, X.-H. Miao, A. L. Abdelhady, T. Wu, O. F. Mohammed and O. M. Bakr, ACS Energy Lett., 2016, 1, 32-37.

14 N. Pellet, P. Gao, G. Gregori, T.-Y. Yang, M. K. Nazeeruddin, J. Maier and M. Grätzel, Angew. Chem., Int. Ed., 2014, 53, 3151-3157.

15 S. Pang, H. Hu, J. Zhang, S. Lv, Y. Yu, F. Wei, T. Qin, H. Xu, Z. Liu and G. Cui, Chem. Mater., 2014, 26, 1485-1491.

16 J. Burschka, N. Pellet, S.-J. Moon, R. Humphry-Baker, P. Gao, M. K. Nazeeruddin and M. Grätzel, Nature, 2013, 499, 316-320.

17 M. Liu, M. B. Johnston and H. J. Snaith, Nature, 2013, 501, 395-398.

18 Q. Chen, H. Zhou, Z. Hong, S. Luo, H. S. Duan, H. H. Wang, Y. Liu, G. Li and Y. Yang, J. Am. Chem. Soc., 2014, 136, 622-625.

19 N. J. Jeon, J. H. Noh, Y. C. Kim, W. S. Yang, S. Ryu and S. Il Seok, Nat. Mater., 2014, 13, 897-903.

20 A. Binek, F. C. Hanusch, P. Docampo and T. Bein, J. Phys. Chem. Lett., 2015, 6, 1249-1253.

21 J. Liu, Y. Shirai, X. Yang, Y. Yue, W. Chen, Y. Wu, A. Islam and L. Han, Adv. Mater., 2015, 27, 4918-4923.

22 C. C. Stoumpos, C. D. Malliakas and M. G. Kanatzidis, Inorg. Chem., 2013, 52, 9019-9038.

23 T. J. Jacobsson, J. P. Correa-Baena, M. Pazoki, M. Saliba, K. Schenk, M. Grätzel and A. Hagfeldt, Energy Environ. Sci., 2016, 9, 1706-1724.

24 M. T. Weller, O. J. Weber, J. M. Frost and A. Walsh, J. Phys. Chem. Lett., 2015, 6, 3209-3212.

25 D. H. Cao, C. C. Stoumpos, C. D. Malliakas, M. J. Katz, O. K. Farha, J. T. Hupp and M. G. Kanatzidis, APL Mater., 2014, 2, 091101. 
26 P. Using, X. Di, T. J. Jacobsson, L. J. Schwan, M. Ottosson, A. Hagfeldt and T. Edvinsson, Inorg. Chem. Front., 2015, 54, 10678-10685.

27 S. Aharon, A. Dymshits, A. Rotem and L. Etgar, J. Mater. Chem. A, 2015, 3, 9171.

28 Y. Chen, M. He, J. Peng, Y. Sun and Z. Liang, Adv. Sci., 2016, 3, 1500392.

29 J. M. Ball, M. M. Lee, A. Hey and H. J. Snaith, Energy Environ. Sci., 2013, 6, 1739.

30 V. D’Innocenzo, A. R. Srimath Kandada, M. De Bastiani, M. Gandini and A. Petrozza, J. Am. Chem. Soc., 2014, 136, 17730-17733.

31 G. Grancini, S. Marras, M. Prato, C. Giannini, C. Quarti, F. De Angelis, M. De Bastiani, G. E. Eperon, H. J. Snaith, L. Manna and A. Petrozza, J. Phys. Chem. Lett., 2014, 5, 3836-3842.

32 D. J. Seol, J. W. Lee and N. G. Park, ChemSusChem, 2015, 8, 2414-2419.

33 L. Wang, C. McCleese, A. Kovalsky, Y. Zhao and C. Burda, J. Am. Chem. Soc., 2014, 110, 12205-12208.

34 Y. Yamada, T. Nakamura, M. Endo, A. Wakamiya and Y. Kanemitsu, J. Am. Chem. Soc., 2014, 136, 11610-11613.

35 S. D. Stranks, V. M. Burlakov, T. Leijtens, J. M. Ball, A. Goriely and H. J. Snaith, Phys. Rev. Appl., 2014, 2, 034007.

36 G. J. A. H. Wetzelaer, M. Scheepers, A. M. Sempere, C. Momblona, J. Ávila and H. J. Bolink, Adv. Mater., 2015, 27, 1837-1841.

37 W. Tress, N. Marinova, O. Inganäs, M. K. Nazeeruddin, S. M. Zakeeruddin and M. Graetzel, Adv. Energy Mater., 2015, 5, DOI: 10.1002/aenm.201400812.

38 N. Marinova, W. Tress, R. Humphry-Baker, M. I. Dar, V. Bojinov, S. M. Zakeeruddin, M. K. Nazeeruddin and M. Grätzel, ACS Nano, 2015, 9, 4200-4209.

39 S. D. Stranks, G. E. Eperon, G. Grancini, C. Menelaou, M. J. P. Alcocer, T. Leijtens, L. M. Herz, A. Petrozza and H. J. Snaith, Science, 2013, 342, 341-344.

40 G. Xing, N. Mathews, S. Sun, S. S. Lim, Y. M. Lam, M. Grätzel, S. Mhaisalkar and T. C. Sum, Science, 2013, 342, 344-347.

41 P. W. Liang, C. Y. Liao, C. C. Chueh, F. Zuo, S. T. Williams, X. K. Xin, J. Lin and A. K. Y. Jen, Adv. Mater., 2014, 26, 3748-3754.

42 Y. Wu, A. Islam, X. Yang, C. Qin, J. Liu, K. Zhang, W. Peng and L. Han, Energy Environ. Sci., 2014, 7, 2934.

43 P. Docampo, F. C. Hanusch, S. D. Stranks, M. Döblinger, J. M. Feckl, M. Ehrensperger, N. K. Minar, M. B. Johnston, H. J. Snaith and T. Bein, Adv. Energy Mater., 2014, 4, 1400355. 44 Z. Xiao, C. Bi, Y. Shao, Q. Dong, Q. Wang, Y. Yuan, C. Wang, Y. Gao and J. Huang, Energy Environ. Sci., 2014, 7, 2619.
45 J. You, Y. (Michael) Yang, Z. Hong, T.-B. Song, L. Meng, Y. Liu, C. Jiang, H. Zhou, W.-H. Chang, G. Li and Y. Yang, Appl. Phys. Lett., 2014, 105, 183902.

46 P. F. Ndione, W.-J. Yin, K. Zhu, S.-H. Wei and J. J. Berry, J. Mater. Chem. A, 2015, 3, 21940-21945.

47 D. Li, S. A. Bretschneider, V. W. Bergmann, I. M. Hermes, J. Mars, A. Klasen, H. Lu, W. Tremel, M. Mezger, H.-J. Butt, S. A. L. Weber and R. Berger, J. Phys. Chem. C, 2016, 120, 6363-6368.

48 H. S. Kim and N.-G. Park, J. Phys. Chem. Lett., 2014, 5, 2927-2934.

49 R. S. Sanchez, V. Gonzalez-Pedro, J. W. Lee, N. G. Park, Y. S. Kang, I. Mora-Sero and J. Bisquert, J. Phys. Chem. Lett., 2014, 5, 2357-2363.

50 H. J. Snaith, A. Abate, J. M. Ball, G. E. Eperon, T. Leijtens, N. K. Noel, S. D. Stranks, J. T. W. Wang, K. Wojciechowski and W. Zhang, J. Phys. Chem. Lett., 2014, 5, 1511-1515.

51 S. Van Reenen, M. Kemerink and H. J. Snaith, J. Phys. Chem. Lett., 2015, 6, 3808-3814.

52 B. Chen, M. Yang, X. Zheng, C. Wu, W. Li, Y. Yan, J. Bisquert, G. Garcia-Belmonte, K. Zhu and S. Priya, J. Phys. Chem. Lett., 2015, 6, 4693-4700.

53 C. Motta, F. El-Mellouhi, S. Kais, N. Tabet, F. Alharbi and S. Sanvito, Nat. Commun., 2015, 6, 7026.

54 Y. Yuan and J. Huang, Acc. Chem. Res., 2015, 49, 286-293.

55 J. J. Choi, X. Yang, Z. M. Norman, S. J. L. Billinge and J. S. Owen, Nano Lett., 2014, 14, 127-133.

56 M. B. Johnston and L. M. Herz, Acc. Chem. Res., 2015, 49, 146-154.

57 E. Guillén, F. J. Ramos, J. A. Anta and S. Ahmad, J. Phys. Chem. C, 2014, 118, 22913-22922.

58 A. R. Pascoe, N. W. Duffy, A. D. Scully, F. Huang and Y.-B. Cheng, J. Phys. Chem. C, 2015, 119, 4444-4453.

59 E. J. Juarez-Perez, R. S. Sanchez, L. Badia, G. Garcia-Belmonte, Y. S. Kang, I. Mora-Sero and J. Bisquert, J. Phys. Chem. Lett., 2014, 5, 2390-2394.

60 J. Bisquert, L. Bertoluzzi, I. Mora-sero and G. Garcia-belmonte, J. Phys. Chem. C, 2014, 118, 18983-18991.

61 O. Almora, I. Zarazua, E. Mas-Marza, I. Mora-Sero, J. Bisquert and G. Garcia-Belmonte, J. Phys. Chem. Lett., 2015, 6, 1645-1652.

62 J. Bisquert, Phys. Chem. Chem. Phys., 2003, 5, 5360.

63 H. Zhou, Q. Chen, G. Li, S. Luo, T.-B. Song, H.-S. Duan, Z. Hong, J. You, Y. Liu and Y. Yang, Science, 2014, 345, 542-546.

64 T. Leijtens, G. E. Eperon, N. K. Noel, S. N. Habisreutinger, A. Petrozza and H. J. Snaith, Adv. Energy Mater., 2015, 5, 1500563.

65 N.-G. Park, Mater. Today, 2015, 18, 65-72. 